\title{
Graves' ophthalmopathy: III. Effect of transantral orbital decompression on optic neuropathy
}

\author{
E SVERKER HALLIN,' STEVEN E FELDON, ${ }^{2}$ AND JEFFREY LUTTRELL ${ }^{2}$
}

From the 'Department of Ophthalmology, University of Göteborg, Sweden; and the ${ }^{2}$ Departments of Ophthalmology and Neurological Surgery, University of Southern California School of Medicine, Los Angeles, California, USA

SUMmaRY Twenty-five patients (48 eyes) underwent transantral, surgical decompression of their orbits for treatment of Graves' ophthalmopathy with optic neuropathy. Visual acuity improved in $77 \%$, remained unchanged in $17 \%$, and worsened in $6 \%$. Colour vision improved in $76 \%$, remained unchanged in $20 \%$, and worsened in $4 \%$. Visual fields improved in $67 \%$, remained unchanged in $12 \%$, and worsened in $22 \%$. In general the worse the vision preoperatively the greater the relative improvement postoperatively. Clinical and radiological findings failed to correlate with visual outcome of surgical intervention. The study shows surgery to be highly effective in restoring optic nerve function for patients with severe Graves' ophthalmopathy.

The optimal treatment of optic neuropathy associated with Graves' ophthalmopathy is controversial. Systemic corticosteroids, ${ }^{1-4}$ high energy irradiation, ${ }^{5-4}$ and surgical decompression ${ }^{2-13}$ of the orbit have all been advocated. Although most authors have reported beneficial effects on visual acuity from surgical decompression, its effects on other aspects of visual function have not been emphasised. The purpose of this report is to quantitate the effect of transantral orbital decompression on the visual acuity, colour vision, and visual fields of 25 patients with Graves' dysthyroid optic neuropathy who failed to respond to high dose systemic corticosteroids.

\section{Patients and methods}

\section{PATIENTS}

Twenty-five patients who underwent surgical decompression of their orbits for treatment of optic neuropathy secondary to Graves' ophthalmopathy were evaluated in a retrospective manner. Of these, 21 patients underwent a single bilateral procedure, two underwent a single unilateral procedure, and two underwent a second bilateral procedure. Nineteen patients were women and six were men; the average age was 58.8 years, range 27 to 83 years. All the patients were examined preoperatively for visual Correspondence to Steven Feldon, MD, Estelle Doheny Eye Foundation, 1355 San Pablo Street, Los Angeles, CA 90033, USA. acuity by Snellen types, colour vision (AO pseudoisochromatic plates), and visual fields (15 patients by Octopus automated perimeter). In addition all the patients had CT scans, all but four of which were evaluated quantitatively to determine the extent of extraocular muscle enlargement. ${ }^{14}$ Visual function tests were repeated at least once after surgery. Table 1 summarises the presenting features of each patient. The data were analysed by standard statistical techniques of correlation and linear regression. Visual fields were analysed by Octopus Program Delta. The average follow-up time was 18.5 months, ranging from a low of one to a high of 49 months.

\section{SURGERY}

Transantral orbital decompression was performed according to the technique described by Walsh and Ogura" and lateral orbital decompression by the technique described by Kroll and Casten. ${ }^{10}$ All patients received at least two weeks of high dose (80-100 mg/day) methylprednisolone (prednisone) prior to surgery; this was gradually tapered for one to three weeks after surgery. Transient or permanent infraorbital anaesthesia was present in the majority of patients. Diplopia, not present preoperatively, was apparent after surgery in 7 of 12 patients. No instances of orbital cellulitis, leak of cerebrospinal fluid, orbital haemorrhage, or catastrophic visual loss were encountered. 
Table 1 Presenting features of 25 patients

\begin{tabular}{|c|c|c|c|c|c|c|c|c|c|c|c|c|c|c|}
\hline Patient & Age & Sex & Eye & $V A$ & $C V$ & Field loss & $A P D$ & $O N$ & Propt. & $T A$ & Exp. & $\%$ Lim. & Strab. & $\begin{array}{l}\% \\
\text { Muscle } \\
\text { volume }\end{array}$ \\
\hline \multirow[t]{2}{*}{1} & 66 & $F$ & $\mathbf{R}$ & $20 / 800$ & $0 / 15$ & $20 \cdot 1$ & + & 1 & 22 & 20 & - & 59 & $25 \mathrm{XT}$ & $15 \cdot 6$ \\
\hline & & & $\mathrm{L}$ & $20 / 40$ & $4 / 15$ & $16 \cdot 9$ & - & 0 & 20 & 24 & - & 45 & & $16 \cdot 8$ \\
\hline \multirow[t]{2}{*}{2} & 82 & F & $\mathrm{R}$ & $20 / 300$ & $0 / 15$ & NA & + & 4 & 22 & 24 & + & 63 & Ortho & $21 \cdot 0$ \\
\hline & & & L & $*$ & * & $*$ & $*$ & $*$ & $*$ & $*$ & $*$ & $*$ & & * \\
\hline \multirow[t]{2}{*}{3} & 39 & $\mathrm{~F}$ & $\mathrm{R}$ & $20 / 50$ & $8 / 15$ & NA & + & 2 & 27 & 27 & + & NA & 10RHT & $20 \cdot 5$ \\
\hline & & & $\mathrm{L}$ & $20 / 30$ & $4 / 15$ & NA & - & 0 & 26 & 24 & - & NA & & $18 \cdot 2$ \\
\hline \multirow[t]{2}{*}{4} & 53 & $\mathbf{F}$ & $\mathbf{R}$ & $20 / 40$ & $11 / 15$ & $21 \cdot 6$ & - & 0 & 22 & 28 & - & 41 & $10 X(T)$ & $12 \cdot 6$ \\
\hline & & & $\mathrm{L}$ & $20 / 60$ & $11 / 15$ & $20 \cdot 6$ & - & 0 & 22 & 31 & - & 43 & & $13 \cdot 8$ \\
\hline \multirow[t]{2}{*}{5} & 31 & $\mathbf{F}$ & $\mathbf{R}$ & $20 / 25$ & $14 / 15$ & NA & - & 0 & 25 & 23 & + & 71 & Ortho & $23 \cdot 4$ \\
\hline & & & L & $20 / 25$ & $12 / 15$ & NA & - & 0 & 26 & 26 & + & 40 & & $24 \cdot 7$ \\
\hline \multirow[t]{2}{*}{6} & 62 & M & $\mathrm{R}$ & $20 / 400$ & $0 / 15$ & $22 \cdot 3$ & + & 2 & 21 & 20 & + & 25 & Ortho & $23 \cdot 0$ \\
\hline & & & $\mathrm{L}$ & $20 / 40$ & $9 / 15$ & $16 \cdot 5$ & - & 2 & 21 & 20 & + & 60 & & 19.5 \\
\hline \multirow[t]{2}{*}{7} & 59 & $\mathbf{M}$ & $\mathbf{R}$ & $20 / 15$ & $15 / 15$ & NA & - & 2 & 25 & 21 & - & 100 & Ortho & $12 \cdot 1$ \\
\hline & & & L & $20 / 25$ & $15 / 15$ & $9 \cdot 5$ & + & 4 & 23 & 30 & - & 55 & & $18 \cdot 1$ \\
\hline \multirow[t]{2}{*}{8} & 56 & M & $\mathbf{R}$ & $20 / 40$ & $13 / 15$ & $0 \cdot 4$ & + & 3 & 29 & 16 & - & 57 & 14RHT & $16 \cdot 0$ \\
\hline & & & $\mathrm{L}$ & $20 / 30$ & $15 / 15$ & $0 \cdot 0$ & - & 3 & 27 & 17 & - & 64 & $8 \mathrm{XT}$ & $14 \cdot 2$ \\
\hline \multirow[t]{2}{*}{9} & 61 & $\mathrm{~F}$ & $\mathbf{R}$ & $20 / 80$ & $9 / 15$ & $12 \cdot 5$ & + & 0 & 26 & 20 & - & 66 & & NA \\
\hline & & & $\mathrm{L}$ & $20 / 60$ & $12 / 15$ & NA & - & 0 & 26 & 12 & - & 66 & 35LHT & NA \\
\hline \multirow[t]{2}{*}{10} & 42 & $\mathrm{~F}$ & $\mathbf{R}$ & $20 / 40$ & $11 / 15$ & 4.9 & - & 0 & 26 & 30 & - & 86 & Ortho & $19 \cdot 0$ \\
\hline & & & $\mathrm{L}$ & $20 / 30$ & $11 / 15$ & $7 \cdot 3$ & + & 0 & 27 & 32 & - & 69 & & $19 \cdot 0$ \\
\hline \multirow[t]{2}{*}{11} & 63 & $\mathrm{~F}$ & $\mathbf{R}$ & $20 / 20$ & $10 / 15$ & $9 \cdot 7$ & - & 4 & 22 & 19 & - & 93 & Ortho & $17 \cdot 0$ \\
\hline & & & $\mathrm{L}$ & $20 / 70$ & $10 / 15$ & 18.9 & + & 0 & 22 & 19 & - & 93 & & $18 \cdot 6$ \\
\hline \multirow[t]{2}{*}{12} & 63 & $\mathbf{F}$ & $\mathbf{R}$ & $20 / 30$ & $8 / 15$ & NA & - & 2 & 26 & 15 & - & 45 & $11 \mathrm{E}(\mathrm{T})$ & $17 \cdot 4$ \\
\hline & & & $\mathrm{L}$ & $20 / 30$ & $7 / 15$ & NA & + & 2 & 27 & 16 & - & 45 & & $16 \cdot 4$ \\
\hline \multirow[t]{2}{*}{13} & 83 & $\mathbf{F}$ & $\mathbf{R}$ & $20 / 200$ & $10 / 15$ & NA & - & 0 & 19 & 20 & + & 22 & Diplopia & NA \\
\hline & & & $\mathrm{L}$ & $20 / 70$ & $8 / 15$ & NA & - & 0 & 19 & 18 & + & 29 & & NA \\
\hline \multirow[t]{2}{*}{14} & 59 & $\mathbf{M}$ & $\mathbf{R}$ & $20 / 80$ & $11 / 15$ & NA & - & 0 & 9 & 24 & - & 35 & Diplopia & $11 \cdot 9$ \\
\hline & & & $\mathrm{L}$ & $20 / 40$ & $11 / 15$ & NA & - & 1 & 7 & 25 & - & 41 & & $14 \cdot 0$ \\
\hline \multirow[t]{2}{*}{15} & 51 & $\mathrm{~F}$ & $\mathbf{R}$ & $20 / 20$ & $12 / 15$ & $0 \cdot 0$ & - & 3 & 25 & 20 & - & 43 & sm.XT & NA \\
\hline & & & $\mathrm{L}$ & $20 / 30$ & $10 / 15$ & $0 \cdot 0$ & - & 3 & 23 & 18 & - & 53 & & NA \\
\hline \multirow[t]{2}{*}{16} & 75 & $\mathrm{~F}$ & $\mathbf{R}$ & $20 / 200$ & $0 / 15$ & NA & + & 4 & 21 & 20 & + & 50 & $35 \mathrm{ET}$ & NA \\
\hline & & & L & $20 / 60$ & $0 / 15$ & NA & - & 0 & 19 & 20 & + & 43 & & NA \\
\hline 17 & 78 & $\mathbf{F}$ & $\mathbf{R}$ & $20 / 200$ & NA & $19 \cdot 9$ & - & 3 & 28 & 19 & + & 38 & Ortho & $21 \cdot 6$ \\
\hline & & & $\mathrm{L}$ & $20 / 400$ & NA & $14 \cdot 6$ & - & 4 & 27 & 22 & + & 40 & & $21 \cdot 5$ \\
\hline 18 & 29 & $\mathrm{~F}$ & $\mathbf{R}$ & $20 / 200$ & $11 / 15$ & $16 \cdot 8$ & + & 3 & 22 & 26 & + & 31 & Ortho & $13 \cdot 2$ \\
\hline & & & $\mathbf{L}$ & $20 / 20$ & $15 / 15$ & $5 \cdot 2$ & - & 2 & 22 & 26 & + & 31 & & $11 \cdot 5$ \\
\hline 19 & 49 & $F$ & $\mathbf{R}$ & $20 / 25$ & $11 / 15$ & $2 \cdot 5$ & - & 2 & 23 & 14 & - & 19 & Ortho & $14 \cdot 5$ \\
\hline & & & L & $30 / 15$ & $12 / 15$ & $4 \cdot 4$ & - & 2 & 23 & 15 & - & 19 & & $12 \cdot 4$ \\
\hline 20 & 72 & $\mathbf{F}$ & $\mathbf{R}$ & $20 / 60$ & $10 / 15$ & $2 \cdot 1$ & - & 3 & 24 & 17 & NA & 33 & Ortho & $19 \cdot 0$ \\
\hline & & & $\mathrm{L}$ & $20 / 60$ & $10 / 15$ & $2 \cdot 3$ & + & 0 & 26 & 17 & NA & 35 & & $20 \cdot 6$ \\
\hline 21 & 27 & $\mathbf{M}$ & $\mathbf{R}$ & $20 / 30$ & $14 / 15$ & 1.5 & - & 0 & 31 & 25 & + & 60 & RHT & $17 \cdot 8$ \\
\hline & & & $\mathrm{L}$ & $20 / 50$ & $13 / 15$ & $3 \cdot 0$ & - & 0 & 30 & 20 & + & 60 & $10 \mathrm{ET}$ & $15 \cdot 2$ \\
\hline 22 & 74 & $\mathrm{~F}$ & $\mathbf{R}$ & $10 / 100$ & $2 / 15$ & NA & - & 2 & 18 & 60 & + & 43 & Diplopia & $26 \cdot 0$ \\
\hline & & & $\mathbf{L}$ & $20 / 200$ & $2 / 15$ & NA & + & 4 & 14 & 14 & + & 43 & & $26 \cdot 9$ \\
\hline 23 & 67 & $\mathbf{F}$ & $\mathbf{R}$ & $20 / 100$ & $8 / 15$ & $5 \cdot 3$ & + & 0 & 23 & 14 & + & 30 & RHT & $13 \cdot 8$ \\
\hline & & & $\mathrm{L}$ & $*$ & $*$ & $*$ & $*$ & * & $*$ & $*$ & $*$ & $*$ & & $*$ \\
\hline 24 & 74 & $\mathbf{M}$ & $\mathbf{R}$ & $20 / 30$ & $10 / 15$ & NA & - & 2 & 24 & 18 & - & 70 & 4RHT & $14 \cdot 5$ \\
\hline & & & $\mathrm{L}$ & $20 / 20$ & $10 / 15$ & NA & - & 2 & 27 & 20 & - & 48 & & $12 \cdot 7$ \\
\hline 25 & 54 & $F$ & $\mathrm{R}$ & $20 / 25$ & $10 / 15$ & NA & - & 2 & 26 & 15 & + & 15 & 4RHT & $10 \cdot 7$ \\
\hline & & & $\mathrm{L}$ & $20 / 25$ & $13 / 15$ & $\mathrm{NA}$ & - & 2 & 25 & 15 & - & 38 & & 9.0 \\
\hline
\end{tabular}

$\mathrm{VA}=$ visual acuity. $\mathrm{CV}=$ colour vision. Field loss $=$ mean decibel whole field loss. $\mathrm{APD}=$ afferent pupillary defect. $\mathrm{ON}=\mathrm{optic}$ nerve status $(0=$ no neuropathy, $1=$ hyperaemia, $2=$ swollen, $3=$ partial atrophy, $4=$ atrophy $)$. Propt.$=$ proptosis. TA=tension applanatation.

Exp. $=$ exposure. $\%$ Lim $=$ total percentage muscle limitation. Strab. $=$ Strabismus present .

$\mathrm{XT}=$ exotropia. Ortho= orthotropia. $\mathrm{RHT}=$ right hypertropia. $\mathrm{LHT}=$ left hypertropia. $\mathrm{E}(\mathrm{T})=\mathrm{intermittent}$ esotropia. $\mathrm{ET}=\mathrm{esotropia}$.

$\mathrm{NA}=$ not available. ${ }^{*}=$ Surgery not performed on that eye.

\section{Results}

DIFFERENCES IN VISUAL FUNCTION FOLLOWING SURGERY

Of the 48 eyes that had surgery 37 (77\%) had improvement in visual acuity postoperatively, eight $(17 \%)$ showed no improvement (five of which had a preoperative visual acuity of $20 / 20$ or better), and three $(6 \%)$ worsened. Of the 25 eyes tested for colour vision pre- and postoperatively the colour vision 


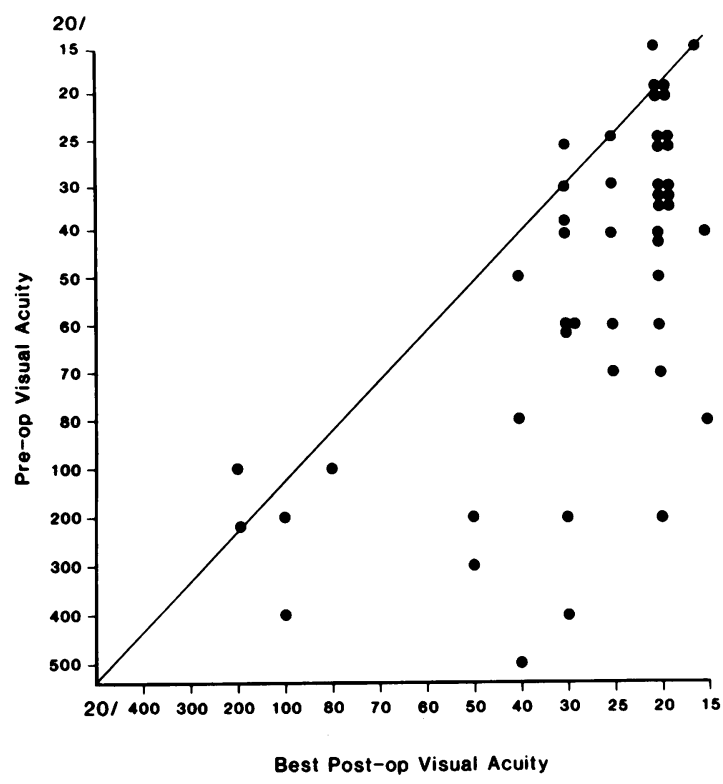

Fig. 1 Scatterplot comparing pre-and postoperative Snellen visual acuity results $(t=-7 \cdot 02, p<0 \cdot 001)$. For this and all succeeding scatterplots the solid line represents 'no change'; points above the line denote a decrease, while points below denote an improvement.

improved in $19(76 \%)$, remained unchanged in five $(20 \%)$ (two of which had a preoperative colour vision of $15 / 15)$, and deteriorated in one (4\%). Of the eyes evaluated by Octopus automated perimetry there was quantitative improvement in $18(67 \%)$, no change in three $(12 \%)$ (all of which showed no preoperative loss), and an increased loss in six $(22 \%)$.

A quantitative analysis of visual parameters was

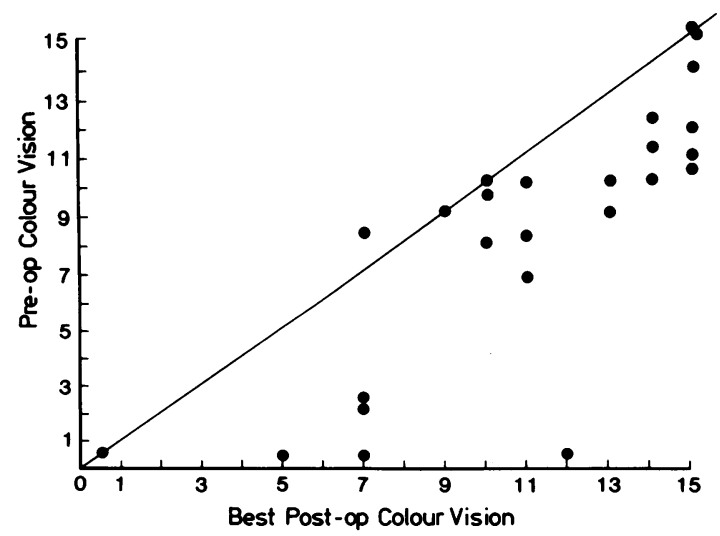

Fig. 2 Scatterplot comparing pre-and postoperative pseudoisochromatic colour vision results $(t=-5 \cdot 33$, $p<0.001)$. performed to determine the amount of change between the preoperative and postoperative assessment. Fig. 1 compares the pre- and postoperative visual acuity by Snellen types for each patient. Fig. 2 compares the pre- and postoperative results of pseudoisochromatic testing of colour vision. In general, patients with higher degrees of visual loss preoperatively had greater improvement after surgery. This tendency was statistically significant, with correlations between preoperative visual acuity and postoperative change being $-0.54(\mathrm{p}<0.001)$, between preoperative colour vision and postoperative change being $-0.74(p<0.001)$, between preoperative central $10^{\circ}$ visual fields and postoperative change being $-0.72(\mathrm{p}<0.001)$, and between preoperative whole visual fields and postoperative change being $-0.60(p<0.001)$.

\section{ASSOCIATION OF NON-VISUAL AND VISUAL PARAMETERS WITH POSTOPERATIVE VISUAL IMPROVEMENT}

Proptosis, limitation of extraocular motility, and extraocular muscle size on CT scan were evaluated as possible predictors of visual outcome following orbital decompression. However, correlations were nearly zero in each instance.

QUANTITATIVE ASSESSMENT OF VISUAL FIELDS The type of visual field loss encountered preoperatively was studied by means of analysis by quadrants, whole $30^{\circ}$ fields, and central $10^{\circ}$ fields. The frequency of encountering visual loss of various degrees in these portions of the field are shown in Fig. 3. The frequency of improvement in visual fields postoperatively for each portion of the field is shown in Fig. 4. A significant correlation was found for postoperative improvement with preoperative severity for the whole field, the lower temporal, the lower nasal, and the central $10^{\circ}$ of field. These correlations are summarised in Table 2.

\section{Discussion}

Quantitative analysis of several parameters of visual function in patients undergoing orbital decompression for Graves' ophthalmopathy with optic neuropathy suggests that surgery is highly effective in restoring all manifestations of optic nerve functionacuity, visual fields, and colour vision. This improvement is especially remarkable in this series of patients because the criterion for surgical decompression was either failure to improve on or drug intolerance to corticosteroids. Morbidity of the procedure was acceptable, with the major complications being diplopia and infraorbital numbness, as has also been reported by others. ${ }^{.15}$ 


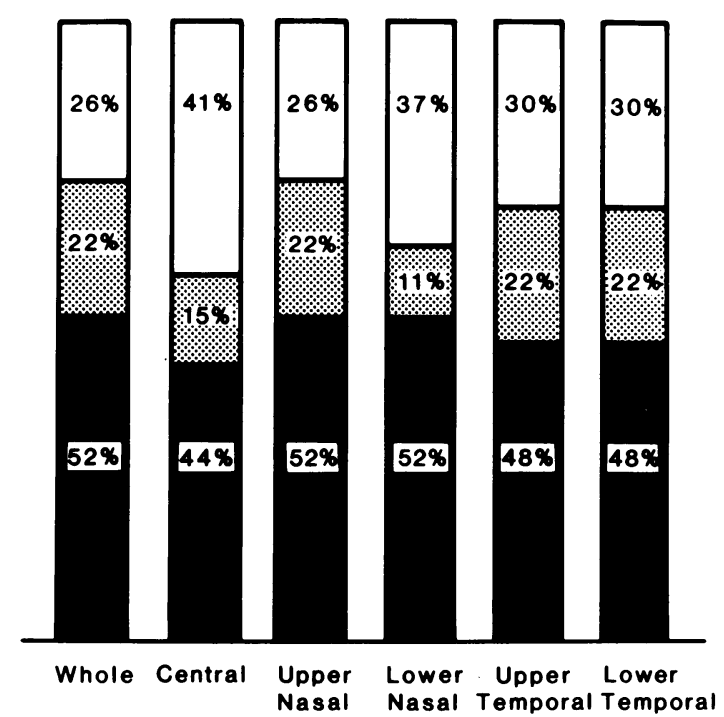

Visual Fields

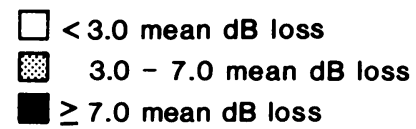

Fig. 3 Bar diagram demonstrating the frequency of preoperative visual field loss: 27 eyes.

Other than the finding first noted by Ogura et al. ${ }^{16}$ that patients with more severe visual dysfunction are more likely to show postoperative improvement, no other parameter of disease, such as preoperative proptosis, motility limitation, or even extraocular muscle enlargement by CT scan seems to aid in predicting which patients are likely to benefit substantially from surgery.

Similar studies to compare quantitatively the results of orbital decompression with other types of treatment for optic neuropathy in Graves' ophthalmopathy are needed. These additional studies should improve the treatment of this vision-threatening disease.

Table 2 Correlations between preoperative visual field mean decibel loss and postoperative improvement

\begin{tabular}{lll}
\hline Visual field & $r$ & $p$ \\
\hline Central & $-0 \cdot 72$ & $<0.001$ \\
Lower temporal & $-0 \cdot 66$ & $<0 \cdot 001$ \\
Lower nasal & $-0 \cdot 63$ & $<0 \cdot 001$ \\
Whole & $-0 \cdot 60$ & $<0 \cdot 001$ \\
Upper temporal & -0.44 & $<0 \cdot 05$ \\
Upper nasal & $-0 \cdot 37$ & NS \\
\hline
\end{tabular}
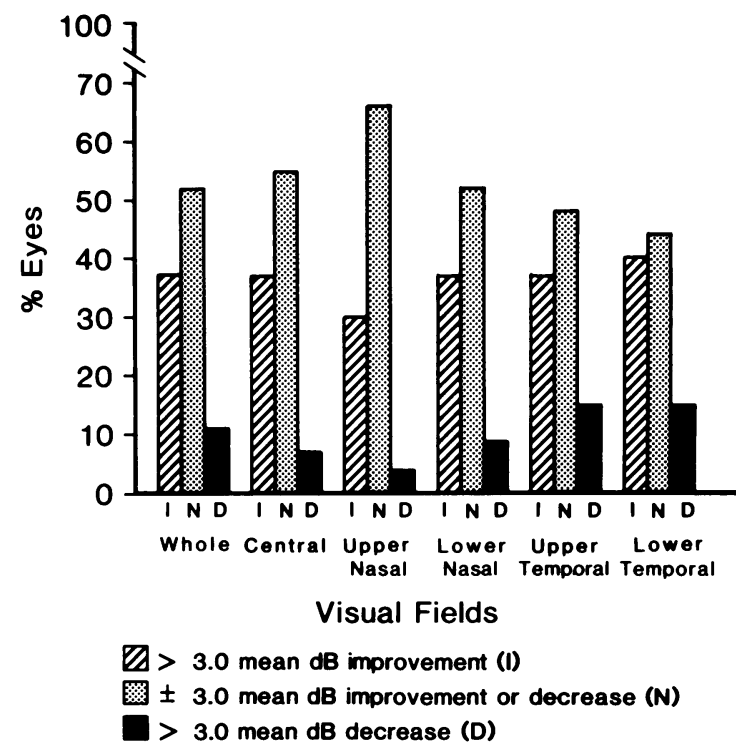

Fig. 4 Bar diagram demonstrating the frequency of postoperative visual field improvement. $\mathrm{I}=$ improvement, $\mathrm{N}=$ no change, $\mathrm{D}=$ decrease.

This study was supported in part by Handlande Herman Svenssons Fund, De Blindas Vanner, and by grant No. EY(03908 awarded by the National Institutes of Health (USA).

\section{References}

1 Brain R, Aterman K, Cope CL. Cortisone in exophthalmos. Report on a therapeutic trial of cortisone and corticotrophin (ACTH) in exophthalmos and exophthalmic ophthalmoplegia by a panel appointed by the Medical Research Council. Lancet 1955; i: 6-9.

2 Brown J, Coburn JW, Wigod RA, Hiss JM Jr, Dowling JT. Adrenal steroid therapy of severe infiltrative ophthalmopathy of Graves' disease. Am J Med 1963; 34: 786-95.

3 Day RM, Carroll FD. Corticosteroids in the treatment of optic nerve involvement associated with thyroid dysfunction. Arch Ophthalmol 1968; 79: 279-82.

4 Mulherin JL Jr, Temple TE Jr, Cundey DW. Glucocorticoid treatment of progressive infiltrative ophthalmopathy. South Med J 1972; 65: 77-80.

5 Donaldson SS, Bagshaw MA, Kriss JP. Supervoltage orbital radiotheraphy for Graves' ophthalmopathy. J Clin Endocrinol Metab 1973; 37: 276-85.

6 Ravin JG, Sisson JC, Knapp WT. Orbital radiation for the ocular changes of Graves' disease. Am J Ophthalmol 1975; 79: 285-8.

7 Covington EE, Lobes L, Sudarsanam A. Radiation therapy for exophthalmos: report of seven cases. Radiology 1977; 122: 797-9.

8 Hurbli T, Char DH, Harris J, Weaver K, Greenspan F, Sheline G. Radiation therapy for thyroid eye diseases. Am J Ophthalmol 1985; 99: 633-7.

9 Long JC, Ellis GD. Temporal decompression of the orbit for thyroid exophthalmos. Am J Ophthalmol 1966; 62: 1089-98.

10 Kroll AJ, Casten VG. Dysthyroid exophthalmos: palliation by lateral orbital decompression. Arch Ophthalmol 1966; 76: 205-10.

11 Walsh TE, Ogura JH. Transantral orbital decompression for malignant exophthalmos. Laryngoscope 1957; 67: 544-68. 
12 Leone CR Jr, Bajandas FJ. Inferior orbital decompression for thyroid ophthalmopathy. Arch Ophthalmol 1980; 98: 890-2.

13 McCord CD Jr. Orbital decompression for Graves' disease exposure through lateral canthal and inferior fornix incision. Ophthalmology 1981; 88: 533-41.

14 Feldon SE, Lee CP, Muramatsu SK, Weiner JM. Quantitative computed tomography of Graves' ophthalmopathy: extraoacular muscle and orbital fat in development of optic neuropathy. Arch Ophthalmol 1985; 103: 213-5.
15 Shorr N, Neuhaus RW, Baylis HI. Ocular motility problems after orbital decompression for dysthyroid ophthalmopathy. Ophthalmology 1982; 89: 323-8.

16 Ogura J, Wessler S, Avioli LV. Surgical approach to the ophthalmopathy of Graves' disease. JAMA 1971; 216: 162731.

Accepted for publication 2 July 1987. 